\title{
Article \\ Phage-Host Interaction Analysis by Flow Cytometry Allows for Rapid and Efficient Screening of Phages
}

\author{
Luís D. R. Melo ${ }^{1,2, * \mathbb{D}}$, Rodrigo Monteiro ${ }^{1,2} \mathbb{D}$, Diana P. Pires ${ }^{1,2}$ and Joana Azeredo $1,2, *(\mathbb{D})$ \\ 1 LIBRO—Laboratório de Investigação em Biofilmes Rosário Oliveira, Centre of Biological Engineering, \\ Campus de Gualtar, University of Minho, 4700-057 Braga, Portugal; rodrigo.m@ceb.uminho.pt (R.M.); \\ priscilapires@deb.uminho.pt (D.P.P.) \\ 2 LABBELS-Associate Laboratory, Braga, 4800-122 Guimarães, Portugal \\ * Correspondence: Imelo@deb.uminho.pt (L.D.R.M.); jazeredo@deb.uminho.pt (J.A.); \\ Tel.: +351-253-601-989 (L.D.R.M.); +351-253-604-414 (J.A.)
}

Citation: Melo, L.D.R.; Monteiro, R.; Pires, D.P.; Azeredo, J. Phage-Host Interaction Analysis by Flow Cytometry Allows for Rapid and Efficient Screening of Phages.

Antibiotics 2022, 11, 164.

https://doi.org/10.3390/ antibiotics11020164

Academic Editor: Adelaide Almeida

Received: 29 December 2021

Accepted: 24 January 2022

Published: 27 January 2022

Publisher's Note: MDPI stays neutral with regard to jurisdictional claims in published maps and institutional affiliations.

Copyright: (C) 2022 by the authors. Licensee MDPI, Basel, Switzerland. This article is an open access article distributed under the terms and conditions of the Creative Commons Attribution (CC BY) license (https:// creativecommons.org/licenses/by/ $4.0 /)$.

\begin{abstract}
Recently, phages have become popular as an alternative to antibiotics. This increased demand for phage therapy needs rapid and efficient methods to screen phages infecting specific hosts. Existing methods are time-consuming, and for clinical purposes, novel, quick, and reliable screening methods are highly needed. Flow cytometry (FC) allows a quick differentiation and enumeration of bacterial cell populations and has been used to assess in vitro the activity of antimicrobial compounds. In this work, we propose FC as a rapid and reliable method to assess the susceptibility of a bacterial population to phage infection. For that, the interaction of phages vB_PaeM_CEB_DP1 and vB_PaeP_PE3 with Pseudomonas aeruginosa PAO1 was characterized by FC. Synchronous infection assays were performed, and samples were collected at different time points and stained with SYTO BC and PI before analysis. Part of the collected samples was used to characterize the expression of early, middle, and late genes by qPCR. Both FC and qPCR results were correlated with phage propagation assays. Results showed that SYTO BC median fluorescence intensity (MFI) values increased in the first $25 \mathrm{~min}$ of PE3 and DP1 infection. The increase of fluorescence is due to the expression of phage genes observed by qPCR. Since SYTO BC MFI values increase with gene expression, it allows the determination of host susceptibility to a phage in a short period of time, avoiding false positives caused by lysis from without. In conclusion, this method may allow for a quick and high-throughput real-time screening of different phages to a specific host, which can be crucial for a quick phage selection in clinical practice.
\end{abstract}

Keywords: Pseudomonas aeruginosa; phages; flow cytometry; phage-host interactions

\section{Introduction}

Bacteriophages (or phages), the most abundant particles on our planet, were discovered in 1915 by Wiliam Twort and, in 1917, Felix d'Hérelle understood their potential to kill bacteria [1]. Despite their discovery at the beginning of the 20th century, only in recent years their popularity has increased, namely due to the lack of efficient therapeutics against the so-called "superbugs", which are multidrug-resistant bacteria. With the current therapeutics, antibiotics, losing efficiency against these emerging pathogens, there is a real threat to public health, which led the World Health Organization (WHO) to elaborate a priority list with the most critical pathogens for the development of new drugs [2]. Phage therapy allows for a tailor-made approach, in which a specific bacteria strain can be treated efficiently with a specific phage, therefore reducing side effects. During the lytic cycle, virulent phages inject their DNA that hijacks the host machinery, generating a high number of copies and producing new phage particles that are released at the end of the cycle with the lysis of the host cell [3]. After phage DNA injection, three stages of replication are started and can be divided into early, middle, and late stages. Phage DNA usually has a modular genetic organization with the genes from each stage of infection being close to each 
other. During the early stage, the phage DNA expresses a group of genes responsible for hijacking host transcription machinery (e.g., RNA-polymerase) to initiate transcription [4]. After controlling the host, several copies of the phage genome are produced and structural proteins are further formed. At the final stage, phage particles are assembled, different phage DNA copies are packed into the capsids, and it ends with the bacterial lysis, releasing the newly formed phage particles [5].

Currently, phage-host interactions are mainly studied using culture-based methods, which are still the gold standard methods but very laborious and time-consuming. Therefore, time-efficient and not labor-intensive techniques have been suggested, such as RNAseq [6], microfluidic-PCR [7], PhageFISH [8], and, more recently, machine learning-based methods. However, these techniques can be expensive and complex to implement and so, here we propose an approach based on Flow Cytometry (FC) to track phage-infected cells. Although FC was developed for mammalian cells, it was further adapted to study bacterial populations [9]. This technique is now part of microbiology research as a consequence of advances in price, sensitivity, and resolution. FC is a potent method that can quantitatively assess bacterial morphology and viability status, having the ability to analyze a bacterial population at the single-cell level in a quick and quantitative manner based on light scattering and fluorescence features. FC has been routinely used for assessing the antimicrobial activity of different compounds by counting and measuring cells and evaluating their viability $[10,11]$. Particularly, the use of live/dead dyes has been gaining interest as it allows a quick enumeration of live, damaged and dead cells [12]. In addition, SYBR Green and SYTO BC can be used as probes to evaluate the physiological state of the cells [13] and how they respond to phage infection [14,15].

In this study, we present FC as a method to monitor the progression of phage infection through live/dead staining using SYTO BC and propidium iodide. We used two different Pseudomonas aeruginosa phages and verified a relation between FC data, phage counts, and gene expression, suggesting that FC is a reliable method to study phage-host interactions and to assess host susceptibility for phage screening.

\section{Results}

\subsection{Real-Time Monitoring of P. aeruginosa PAO1 Infection with Two Different Phages Using} Flow Cytometry

The dynamics of P. aeruginosa PAO1 and phage PE3 (Podoviridae) and DP1 (Myoviridae) interactions were determined on a flow cytometer using LIVE/DEAD fluorochromes. To compare what is happening through phage infection in terms of replication (by PFU determination and RT-qPCR) and flow cytometry, it was necessary to achieve a synchronous infection using high MOIs. Consequently, both phages were applied at a MOI of 50 and, after 5 min of incubation with the dyes, samples were analyzed on the flow cytometer to assess bacterial viability and enumeration (Figure 1, Supplementary Figure S1).

a)

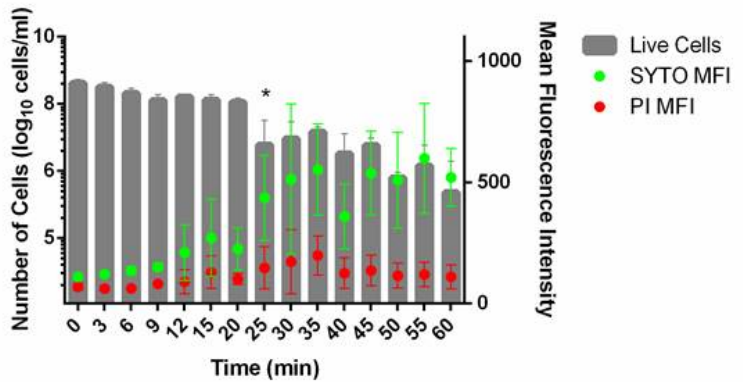

b)

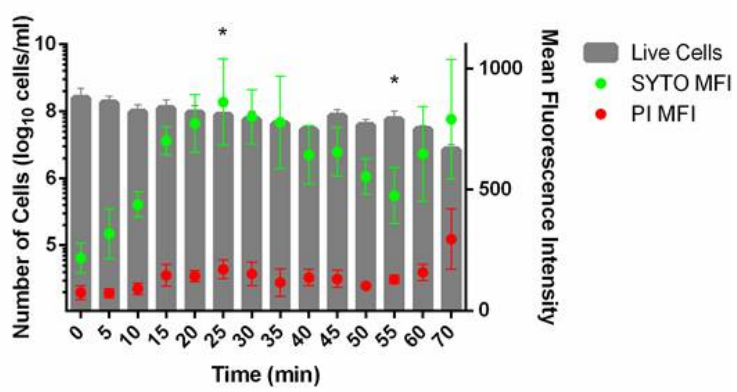

Figure 1. Flow cytometric analysis of P. aeruginosa PAO1 cells infected with (a) phage PE3 and (b) phage DP1. On the left yy axis are represented the total cell counts and on the right yy axis the median intensity fluorescence of SYTO and PI. Values represent the mean plus or minus standard deviation of four independent experiments performed in duplicate. Statistical differences $\left({ }^{*} p<0.05\right)$ were analyzed using ANOVA with Tukey's honest significant difference post hoc test. 
Regarding infection assays with phage PE3, we observed that the initial number of bacterial cells was approximately $3.04 \times 10^{8}$ cells $/ \mathrm{mL}$ (Figure 1a). This number was stable during the first $20 \mathrm{~min}$ of phage infection. At $25 \mathrm{~min}$ of infection, there was a decrease in the number of cells of approximately 2 orders of magnitude $\left(8.3 \times 10^{6}\right.$ cells $\left./ \mathrm{mL}\right)$. The number of cells kept stable until the $50 \mathrm{~min}$ time point, and at $60 \mathrm{~min}$ of infection, the number of cells was reduced in about 1 order of magnitude $\left(7.5 \times 10^{5}\right.$ cells $\left./ \mathrm{mL}\right)(p<0.05)$. Regarding SYTO MFI, it is possible to observe, within the first $20 \mathrm{~min}$ of infection, a slight consistent increase, but without statistical significance. After $25 \mathrm{~min}$ of infection, a significant increase on SYTO MFI was noticed $(p<0.05)$ from $91 \pm 12(0 \mathrm{~min})$ to $163 \pm 20(p<0.05)$. From $25 \mathrm{~min}$ to $50 \mathrm{~min}$ of infection, a SYTO MFI constant increasing tendency was also detected. Concerning PI, it is possible to observe that there were no significant changes in the MFI during the first $60 \mathrm{~min}$ of infection.

When P. aeruginosa PAO1 was infected with phage DP1, the initial number of cells was approximately $2.5 \times 10^{8}$ cells $/ \mathrm{mL}$ (Figure $1 \mathrm{~b}$, Supplementary Figure S2). The number of detected cells was stable until $40 \mathrm{~min}$ of infection, where a reduction of approximately 1 order of magnitude was observed $\left(2.8 \times 10^{7}\right.$ cells $\left./ \mathrm{mL}\right)$. Moreover, the number of cells kept stable until $60 \mathrm{~min}$ of infection and at $70 \mathrm{~min}$ of phage infection the number of cells was significantly less $\left(8.29 \times 10^{6}\right.$ cells $\left./ \mathrm{mL}\right)$. Flow cytometry results indicate a constant increase of SYTO MFI during the first $25 \mathrm{~min}$ of infection (from $186 \pm 52$ to $352 \pm 85(p<0.05)$ ). After $25 \mathrm{~min}$ and until $55 \mathrm{~min}$ of infection, the MFI decreased constantly until reaching $299 \pm 36(p<0.05)$. In the last minutes of infection, a new SYTO MFI increasing tendency until reaching $605 \pm 44(p<0.05)$ was noticed. Regarding PI, there were no significant changes in the MFI between the first $60 \mathrm{~min}$ of infection, and a significant increase was observed from 60 to 70 min of infection $(p<0.05)$.

\subsection{Phage Replication Assessed through Plaque Forming Units Counting}

The dynamics of $P$. aeruginosa PAO1 infection with phages PE3 and DP1 at a MOI $=50$ were assessed by PFU determination (Figure 2). The number of PFUs of PE3 phage was stable during the first $20 \mathrm{~min}$ of infection and significantly increased after $25 \mathrm{~min}$ of infection $(* p<0.05)$. Afterwards, the number of PFUs was constant until the end of the assay (Figure 2a). Regarding phage DP1, a PFU decreasing tendency until 25 min of infection was observed (Figure 2b). After that time point, the number of PFUs gradually increased until reaching the end of the assay at $70 \min \left({ }^{*} p<0.05\right)$.

a)

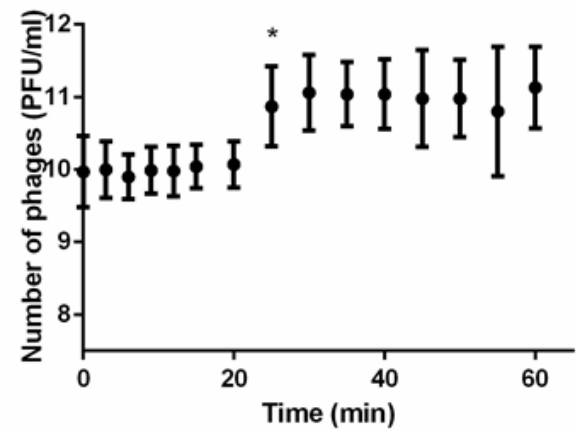

b)

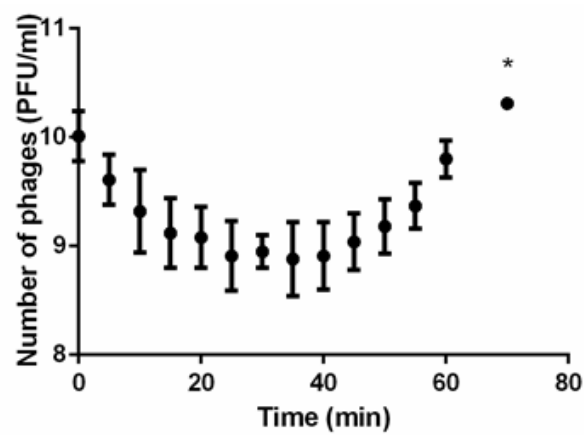

Figure 2. Number of PFUs evaluated during phage infection at a MOI = 50 of (a) phage PE3 and (b) phage DP1 phage in P. aeruginosa PAO1 cells. Data points represent the mean plus or minus standard deviation of three independent experiments. Statistical differences $\left({ }^{*} p<0.05\right)$ were analyzed with one-way ANOVA with Tukey's honest significant difference post hoc test.

\subsection{Gene Expression}

The transcription of phage genes is temporally regulated over the course of the lytic phage cycle. To relate flow cytometry data with phage replication, the expression levels of different genes were assessed at different time points post-infection according to their replication cycle (Figure 3). To provide a clear idea of what happens during transcription, 
gene expression levels were compared to the previous time point, instead of comparing all to t0.

a)

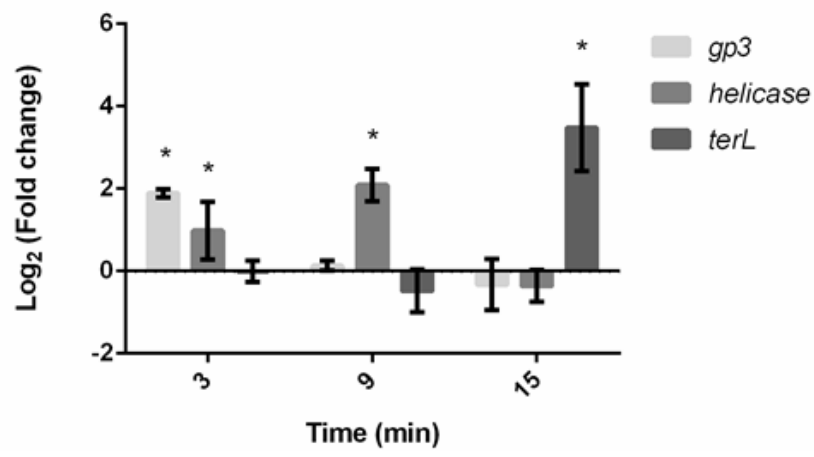

b)

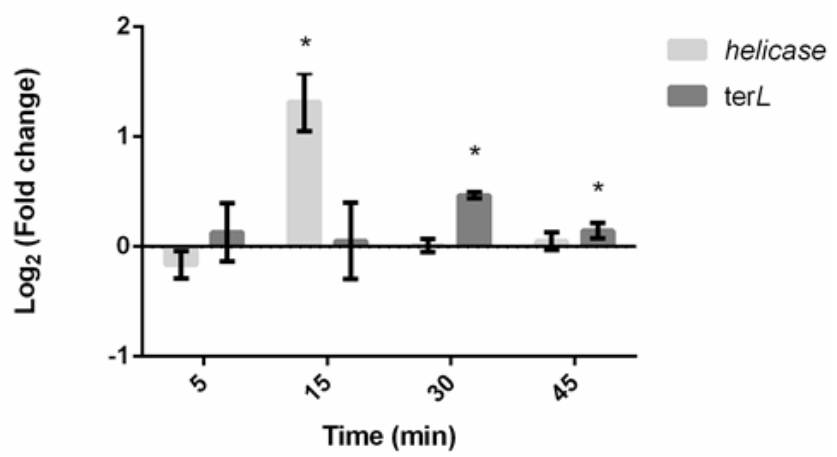

Figure 3. Gene expression of phage PE3 (a) and phage DP1 (b) after P. aeruginosa PAO1 infection with a MOI of 50 at different time points. The quantification of mRNA transcripts was determined using a variation of the Livak method $\left(\mathrm{E}^{\Delta \mathrm{Ct}}\right)$, with $16 \mathrm{~S}$ rRNA as a reference gene and non-infected cells as a control. The values represent the mean plus or minus standard deviation of two independent experiments performed in triplicate. Statistical differences $\left({ }^{*} p<0.05\right)$ were analyzed using ANOVA with Tukey's honest significant difference post hoc test.

Regarding phage PE3, the levels of gp3 increased significantly during the first $3 \mathrm{~min}$ of infection $(p<0.05)$. This was expected, as this gene is referred to as an early gene of phage replication cycle [16] (Figure 3a). The levels of expression of this gene were stable during 9 min of infection and decreased after 15 min of phage-host interaction $(p<0.05)$. Helicase (hel) is a middle gene, which was overexpressed after 3 min of infection, but the maximum levels were detected at the 9 min time point $(p<0.05)$. As expected, the late gene terminase large subunit (terL) was only overexpressed at the 15 min time point $(p<0.05)$.

As phage DP1 has a longer replication cycle, the time points selected to study phage replication were $5,15,30$, and $45 \mathrm{~min}$ (Figure $3 \mathrm{~b}$ ). As no early gene was reported on this phage, only a middle (hel) and a late (terL) gene were studied. The transcripts of hel were not detected at $5 \mathrm{~min}$ of infection, and the maximum level of transcripts was observed at 15 min of infection $(p<0.05)$. Afterwards, the levels were kept constant. Regarding terL, no overexpression was detected at the first $15 \mathrm{~min}$ of infection. Moreover, the maximum expression levels were observed at 45 min of infection $(p<0.05)$.

\section{Discussion}

Our previous experience with the application of flow cytometry to study phage-host interactions was focused on the interaction of a phage with Staphylococcus epidermidis host cells in different metabolic/physiological states [14], and also on the study of phage and honey treatments on the viability of Escherichia coli biofilms [15] using an adaptation of the LIVE/DEAD staining. In the present study, we intended to further expand this technique for real-time assessment of phage-bacteria interactions as a reliable and fast method to assess host susceptibility to phages, overcoming the time-consuming plating methods. Flow cytometry is broadly applied in biological sciences and has been gaining interest in the bacteriophage field. In 2009, Brussaard described a methodology to enumerate phages using SYBR ${ }^{\circledR}$ Green I [17]. In another study, the flow cytometry analysis of phagemediated killing of Enterobacter aerogenes cells has identified a culture-based bias during plate culture [18]. Besides cell counting, flow cytometry also allowed the study of cell physical differences [19]. The authors noticed that at the end of infection, phage-infected cells had low-density cell walls that were noticed on cytograms. More recently, Low et al. tagged two Pseudomonas phages with Syto13 and evaluated their binding, infection, and killing by flow cytometry. 
To guarantee that all cells are infected at the same time, synchronous infections were used. These infections have been used, for example, to study the molecular profiling of infection through qPCR [20] or RNA-Seq [16,21], and even suggested to study one-step growth curves [22]. Here, to guarantee a synchronous infection of $P$. aeruginosa PAO1 with phages PE3 and DP1, a MOI of 50 was used. A similar MOI was used by Lood et al. [23] to study PA5oct jumbo phage by RNA-Seq.

The results obtained in this study show that flow cytometric live/dead assay is a useful method to follow the progression of $P$. aeruginosa phage infection and can be potentially applied to other phage/host pairs. Both SYTO BC and PI stain both DNA and RNA, therefore, during the first 25 min of infection, an increase of the metabolic activity [24] due to an accumulation of phage transcripts was observed, which is explained by the increase of SYTO MFI. Interestingly, the SYTO and PI MFI correlates well with the phage life cycle determined by PFU measurements. For example, for phage DP1, the decrease in PFU counts that occurred during the first 25 min (Figure 2b), which is related to phage adsorption and infection corresponds to an increase in SYTO MFI. After $25 \mathrm{~min}$, the first burst occurs with the increase in PFU numbers, whereas the median SYTO MFI decreases and PI MFI increases, corresponding to a decrease in phage transcripts and increase of cell damage [25]. It was exactly at $70 \mathrm{~min}$ of infection when it was observed an increase in the number of PFUs (Figure 2b). Regarding phage PE3, the increase in SYTO MFI was prolonged until $55 \mathrm{~min}$ of infection (Figure 1a). At 25 and $55 \mathrm{~min}$ of infection, it was also observed a significant decrease in the number of cell counts. This data is consistent with the PFU counts obtained (Figure 2a), showing that both first and second bursts are detectable on a flow cytometer.

Phage genes are temporally expressed and are divided into early, middle, and late genes due to their order of expression in phage replication cycle [26]. After observing the quick response of $P$. aeruginosa PAO1 cells to phage addition, qPCR experiments were performed to assess the differences in the expression of phage genes and their relation to what was observed on the flow cytometry analysis. In the case of phage DP1, no early gene was identified. As expected, it was at mid points where the maximum transcriptional levels were observed (9 min for PE3 and 15 min for DP1), suggesting that in both cases phage DNA was being replicated in P. aeruginosa PAO1 cells. Late genes are usually involved in lysis, morphogenetic, or DNA packaging functions. Regarding ter $L$, overexpression was observed at 9 min on cells infected by phage PE3 and at 30 and 45 min on cells infected by phage DP1, suggesting that structural proteins were already produced and phage DNA was ready to be translocated into empty capsids [27]. It was interesting to observe that the qPCR data are well aligned with the flow cytometry results. During the first minutes of infection, only early genes were expressed. These genes are responsible for host takeover and generally do not lead to a significant increase in transcripts. These experiments were performed on highly active exponential-phase cells and, as previously suggested, it is not expected that phage infection can lead to an increase of mRNA transcripts and consequent SYTO MFI increase [14]. In the middle phase of phage lytic cycle occurs phage DNA replication. In this phase, an increase in mRNA transcripts, which was observable for PE3 (6 to 25 min of infection) and DP1 (5 to 25 min of infection), is expected. Recently, using RNA-Seq data, it was shown that the increase of phage transcripts is associated with a decrease in the production of host transcripts. As phage DP1 possesses a longer cycle of replication than phage PE3, the decrease on SYTO MFI observed from 25 to 55 min of infection might be associated with a lesser amount of total mRNA transcripts on $P$. aeruginosa. In the late stage of phage infection, after terL being highly expressed, an increase of SYTO MFI that is associated with the formation of new phage particles inside the host was observed, which leads to an increase in the total amount of nucleic acids. Globally, our qPCR results clearly demonstrate that both phages are modular, in which several transcriptional units are differentially expressed during phage infection [6].

It is important to emphasize that the design of a flow cytometry protocol to analyze phage infection requires an appropriate selection of rigorous controls to define properly 
specific and unspecific staining. Naturally, due to the high diversity of phages and their hosts, it might be necessary to perform several adjustments for each studied interaction. For example, MOI might need to be adapted to each host tested. To overcome this, a range of different MOIs can be tested at the same time. Despite this little disadvantage on the use of flow cytometry, there are numerous pros that should be taken into consideration. With live/dead staining, it is possible to count the number of bacterial cells in real time (with 10 min of delay due to staining) in comparison with plating techniques that usually need at least an overnight incubation, but on the case of fastidious bacteria can be dramatically longer.

In conclusion, with the increasing interest in phage therapy, the selection of appropriate methods for screening suitable phages for therapy is of utmost importance. In this sense, the use of flow cytometry can reduce the time needed to select the appropriate phage for therapy. Another advantage of using flow cytometric methods is the possibility of allowing a more detailed and precise selection of phages, by having in a short time several parameters like latency period, selection of specific time points for further studies, and number of live bacterial cells in an established period of time. This is a proof of concept that proved to be potentially useful and can be improved by analyzing different types of bacteria (Gram-negative and Gram-positive) and phages to formulate a more universal protocol. In the near future, this could contribute to identify key factors involved in the success of phage therapy [28].

\section{Materials and Methods}

\subsection{Bacterial Strain and Phages}

In this study, the P. aeruginosa PAO1 (DSM22644) reference strain from the German Collection of Microorganisms and Cell Cultures was used. The bacterial cultures were grown at $37^{\circ} \mathrm{C}$ in lysogeny broth (LB, NZytech, Lisbon, Portugal), LB agar or LB soft agar overlays containing $1.5 \%(w / v)$ or $0.6 \%(w / v)$ of agar, respectively. The two P. aeruginosa phages used in this work were previously isolated and characterized as vB_PaeM_CEB_DP1 (short name DP1) [29] and vB_PaeP_E3 (short name PE3) [30].

\subsection{Phage Production and Titration}

Phages were propagated using the double agar overlay technique [31]. Briefly, $10 \mu \mathrm{L}$ of isolated phage lysate was added to LB agar plates containing the P. aeruginosa PAO1 lawn and spread using a paper strip. The Petri dishes were then incubated at $37^{\circ} \mathrm{C}$ for 16-18 h. After incubation and checking full lysis, $3 \mathrm{~mL}$ of saline magnesium buffer (SM buffer) (5.8 g/L NaCl, $2 \mathrm{~g} / \mathrm{L} \mathrm{MgSO}_{4} 7 \mathrm{H}_{2} \mathrm{O}, 50 \mathrm{~mL} / \mathrm{L} 1 \mathrm{M}$ Tris- $\left.\mathrm{HCl} \mathrm{pH} 7.5\right)$ were added to the Petri dishes. Plates were further placed under agitation at $4{ }^{\circ} \mathrm{C}$ for $18 \mathrm{~h}$. Thereafter, the liquid phase was collected, centrifuged for $10 \mathrm{~min}, 9000 \times \mathrm{g}, 4^{\circ} \mathrm{C}$ and the supernatant was recovered, filtered through a $0.22 \mu \mathrm{m}$ PES membrane (Whatman, Maidstone, UK) and stored at $4{ }^{\circ} \mathrm{C}$ until further use.

For phage titration, plaque forming unit (PFU) assay was performed using the double agar overlay technique [32]. Serial dilutions of phage stock solutions in SM buffer were performed. Then, $100 \mu \mathrm{L}$ of the diluted phage solution was mixed with $100 \mu \mathrm{L}$ of the bacterial host and $3 \mathrm{~mL}$ of LB soft agar into a Petri dish already containing a layer of LB agar. The plates were incubated overnight at $37^{\circ} \mathrm{C}$ and the PFUs were counted.

\subsection{Synchronized Infection Assays}

Synchronized infection experiments were performed with phages DP1 and PE3 according to a procedure published elsewhere [16]. Briefly, P. aeruginosa cells were grown overnight, diluted 1:100 in $20 \mathrm{~mL}$ of fresh LB media, and incubated at $37^{\circ} \mathrm{C}$ and $120 \mathrm{rpm}$, until reaching an optical density $\left(\mathrm{OD}_{600 \mathrm{~nm}}\right)$ of 0.3 , which corresponds to approximately $2 \times 10^{8} \mathrm{CFU} / \mathrm{mL}$. After, $10 \mathrm{~mL}$ of the bacterial culture were transferred to a new Erlenmeyer and mixed with the phage PE3 or DP1 at a multiplicity of infection (MOI) of 50 to ensure a synchronized infection of the culture. One sample of the infected culture was im- 
mediately taken $(t=0)$ and the culture was then incubated at $37^{\circ} \mathrm{C}$ with agitation $(120 \mathrm{rpm})$. Several samples were subsequently taken at selected time-points for PFU quantification, flow cytometry analysis, and RNA extraction.

\subsection{Phage Quantification}

The number of phages was tracked during the synchronized infection through the enumeration of PFUs at selected time points. For phage PE3, samples were collected every 3 min during the first 15 min of infection, and afterwards, with a 5 min interval for $60 \mathrm{~min}$ of infection; for phage DP1, samples were taken every 5 min during the 70 min of infection. Each sample was taken and directly diluted several times in SM buffer prior to plating. Three independent experiments were performed in duplicate.

\subsection{Flow Cytometry}

$P$. aeruginosa cell viability was assessed by flow cytometry before and after phage infection, as previously optimized, with minor modifications [33]. For phage PE3, samples were collected every 3 min during the first 15 min of infection, and afterwards, with a 5 min interval during one hour of infection. Concerning phage DP1, samples were taken every 5 min during the $70 \mathrm{~min}$ of infection. Briefly, $30 \mu \mathrm{L}$ of bacterial suspension were added to $270 \mu \mathrm{L}$ of a solution containing $250 \mathrm{nM}$ of SYTO ${ }^{\circledR}$ BC Green Fluorescent Nucleic Acid Stain (Thermo Fisher Scientific, Waltham, MA, USA) and $20 \mu \mathrm{g} / \mathrm{mL}$ of propidium iodide (PI) (Thermo Fisher Scientific, Waltham, MA, USA) and incubated 10 min at room temperature. The fluorescence of bacteria was measured using an EC800 (SONY, San Jose, CA, USA) flow cytometer equipped with an argon ion laser emitting at $488 \mathrm{~nm}$. An acquisition protocol was defined to measure green fluorescence (FL1 channel), red fluorescence (FL4 channel), forward scatter (FS) and side scatter (SS). For all detected parameters, amplification was carried out using logarithmic scales. Data were acquired and analyzed using Sony EC800 Flow Cytometry Analyzer software. Four independent experiments were performed in duplicate.

\subsection{RNA Extraction}

Total RNA was isolated from synchronized infection experiments at selected timepoints: 3, 9, and $15 \mathrm{~min}$ for PE3 phage, and 5, 15, 30, and $45 \mathrm{~min}$ for phage DP1 infection. Immediately before phage infection, a sample of bacterial culture was taken to be used as a control (t0). At each time-point, a $450 \mu \mathrm{L}$ sample was collected, immediately mixed/vortexed with $50 \mu \mathrm{L}$ of pre-chilled stop-solution (1:10 buffered phenol, 9:10 absolute ethanol), and incubated on ice until all samples were collected. The samples were then harvested by centrifugation $\left(9000 \times g, 5 \mathrm{~min}, 4^{\circ} \mathrm{C}\right)$, and the RNA was extracted from the cell pellets using the Purelink RNA Mini Kit (Invitrogen) according to the manufacturer's instructions. The RNA concentration was measured in a NanoDrop (ThermoFisher Scientific, Waltham, MA, USA) and samples were treated with DNase I (ThermoFisher Scientific, Waltham, MA, USA) for $30 \mathrm{~min}$ at $37^{\circ} \mathrm{C}$ to remove genomic DNA. The enzyme was then heat-inactivated at $65^{\circ} \mathrm{C}$ for $10 \mathrm{~min}$ in the presence of EDTA. RNA concentration and purity $\left(A_{260} / A_{280}\right.$ and $\left.A_{260} / A_{230}\right)$ were determined by NanoDrop (Thermo Fisher Scientific, Waltham, MA, USA) and RNA integrity was inferred by visualization of the 23S/16S rRNA banding pattern using a $1 \%$ non-denaturing agarose gel.

\subsection{Gene Expression Quantification}

Quantitative PCR (qPCR) was used to assess the expression of the following genes: gp3, helicase (hel) and terminase large subunit (terL) for phage PE3; and helicase (hel) and terminase large subunit (terL) for phage DP1. In addition, 16S rRNA gene of $P$. aeruginosa was used as a reference gene. The primers were manually designed using the $P$. aeruginosa PAO1 DSM22644 genome as a template (AE004091), or P. aeruginosa phage PE3 (MN901924) or $P$. aeruginosa phage DP1 (KR869157). The sequences of the primers used are listed in Table 1. 
Table 1. Primers used in this study.

\begin{tabular}{cccc}
\hline Primer & Sequence $\left(\mathbf{5}^{\prime} \rightarrow \mathbf{3}^{\prime}\right)$ & Amplicon Size (bp) & Description \\
\hline $\begin{array}{c}\text { PE3_TerL_Fwd } \\
\text { PE3_TerL_Rev }\end{array}$ & $\begin{array}{c}\text { GCAATGAGCGTTCCGTGTTCC } \\
\text { CCATTCCTTCTTGGCAGCCTC }\end{array}$ & 176 & $\begin{array}{c}\text { Amplify phage PE3 terminase, large } \\
\text { subunit }\end{array}$ \\
\hline $\begin{array}{c}\text { PE3_hel_Fwd } \\
\text { PE3_hel_Rev }\end{array}$ & $\begin{array}{c}\text { GCGCATCAGAAGGTAGACC } \\
\text { GGTTGTACTGCGCCAGGAG }\end{array}$ & 204 & Amplify phage PE3 DNA helicase \\
\hline $\begin{array}{l}\text { PE3_gp3_Fwd } \\
\text { PE3_gp3_Rev }\end{array}$ & $\begin{array}{c}\text { CGTGGTACAGCTTCAAGCC } \\
\text { AGGTCACCCAGCAGTTCC }\end{array}$ & 139 & Amplify phage PE3 gp3 \\
\hline $\begin{array}{l}\text { DP1_TerL_Fwd } \\
\text { DP1_TerL_Rev }\end{array}$ & $\begin{array}{c}\text { GAAGCTTATGAGCGCGACC } \\
\text { CCGATGCGCTTCGATCC }\end{array}$ & 159 & Amplify phage DP1 terminase, large \\
DP1_hel_Fwd & CAGGTTGCGCTTCCACTC & 171 & Amplify phage DP1 DNA helicase \\
DP1_hel_Rev & GCAGACGTGGCCATCTAC & &
\end{tabular}

Total RNA samples were reverse transcribed using Xpert cDNA Synthesis Mastermix (Grisp, Porto, Portugal), following manufacturer's instructions. Control reactions lacking the reverse transcriptase enzyme (no-RT) were included. qPCR reactions contained $2 \mu \mathrm{L}$ of 1:100 diluted cDNA or no-RT control, $1 \mu \mathrm{L}$ containing 10 pmol of each primer, $2 \mu \mathrm{L}$ nuclease-free deionized $\mathrm{H}_{2} \mathrm{O}$, and $5 \mu \mathrm{L}$ Xpert Fast SYBR 2X Mastermix (Grisp), with the following thermal cycler parameters: $95^{\circ} \mathrm{C}$ for $2 \mathrm{~min}, 40$ cycles of $95^{\circ} \mathrm{C}$ for $5 \mathrm{~s}$ and $60^{\circ} \mathrm{C}$ for $30 \mathrm{~s}$. To monitor the reaction specificity and primer dimer formation, end-products were analyzed by melting curves. A mock qPCR reaction lacking the cDNA template was used. The quantification of mRNA transcripts, for each gene under study, was determined using the Pfaffl method [34]. Data analysis was based on two independent experiments performed in triplicate.

\subsection{Statistical Analysis}

The assays were compared using two-way ANOVA and Tukey's honest significant difference post hoc test, using Prism 6 (GraphPad, La Jolla, CA, USA). Data are depicted as mean and standard deviation. Differences among conditions were considered statistically significant when $p<0.05$.

Supplementary Materials: The following supporting information can be downloaded at: https: / / www.mdpi.com/article/10.3390/antibiotics11020164/s1, Figure S1: Flow cytometric analysis of P. aeruginosa PAO1 infected with phage E3, using a MOI of 50; Figure S2: e 2. Flow cytometric analysis of $P$. aeruginosa PAO1 infected with phage DP1, using a MOI of 50 .

Author Contributions: L.D.R.M. and J.A. conceived and designed the experiments; L.D.R.M., R.M. and D.P.P. performed the experiments; L.D.R.M., R.M., D.P.P. and J.A. analyzed the data; L.D.R.M. wrote the paper. All authors have read and agreed to the published version of the manuscript.

Funding: This study was supported by the Portuguese Foundation for Science and Technology (FCT) under the scope of the strategic funding of UIDB/04469/2020 unit, and Projects PTDC/SAUPUB/29182/2017 [POCI-01-0145-FEDER-029182] and PTDC/BIA-MIC/2312/2020. RM is recipient of a FCT PhD grant with the reference SFRH/BD/143639/2019.

Conflicts of Interest: The authors declare no conflict of interest.

\section{References}

1. Clokie, M.R.; Millard, A.D.; Letarov, A.V.; Heaphy, S. Phages in nature. Bacteriophage 2011, 1, 31-45. [CrossRef] [PubMed]

2. WHO Publishes List of Bacteria for Which New Antibiotics Are Urgently Needed. Available online: https://www.who.int/news/ item/27-02-2017-who-publishes-list-of-bacteria-for-which-new-antibiotics-are-urgently-needed (accessed on 31 December 2021).

3. Sulakvelidze, A.; Alavidze, Z.; Morris, J.G., Jr. Bacteriophage Therapy. Antimicrob. Agents Chemother. 2001, 45, 649-659. [CrossRef] [PubMed] 
4. Yang, H.; Ma, Y.; Wang, Y.; Yang, H.; Shen, W.; Chen, X. Transcription regulation mechanisms of bacteriophages: Recent advances and future prospects. Bioengineered 2014, 5, 300-304. [CrossRef] [PubMed]

5. Roucourt, B.; Lavigne, R. The role of interactions between phage and bacterial proteins within the infected cell: A diverse and puzzling interactome. Environ. Microbiol. 2009, 11, 2789-2805. [CrossRef]

6. $\quad$ Leskinen, K.; Blasdel, B.G.; Lavigne, R.; Skurnik, M. RNA-Sequencing Reveals the Progression of Phage-Host Interactions between $\varphi \mathrm{R} 1-37$ and Yersinia enterocolitica. Viruses 2016, 8, 111. [CrossRef]

7. Tadmor, A.D.; Ottesen, E.A.; Leadbetter, J.R.; Phillips, R. Probing Individual Environmental Bacteria for Viruses by Using Microfluidic Digital PCR. Science 2011, 333, 58-62. [CrossRef]

8. Barrero-Canosa, J.; Moraru, C. PhageFISH for Monitoring Phage Infections at Single Cell Level. Methods Mol. Biol. 2019, 1898, 1-26. [CrossRef]

9. Álvarez-Barrientos, A.; Arroyo, J.; Cantón, R.; Nombela, C.; Sánchez-Pérez, M. Applications of Flow Cytometry to Clinical Microbiology. Clin. Microbiol. Rev. 2000, 13, 167-195. [CrossRef]

10. Grainha, T.; Magalhães, A.P.; Melo, L.D.R.; Pereira, M.O. Pitfalls Associated with Discriminating Mixed-Species Biofilms by Flow Cytometry. Antibiotics 2020, 9, 741. [CrossRef]

11. Teixeira, P.; Fernandes, B.; Silva, A.M.; Dias, N.; Azeredo, J. Evaluation by Flow Cytometry of Escherichia coli Viability in Lettuce after Disinfection. Antibiotics 2019, 9, 14. [CrossRef] [PubMed]

12. Berney, M.; Hammes, F.; Bosshard, F.; Weilenmann, H.-U.; Egli, T. Assessment and Interpretation of Bacterial Viability by Using the LIVE/DEAD BacLight Kit in Combination with Flow Cytometry. Appl. Environ. Microbiol. 2007, 73, 3283-3290. [CrossRef] [PubMed]

13. Cerca, F.; Trigo, G.; Correia, A.; Cerca, N.; Azeredo, J.; Vilanova, M. SYBR green as a fluorescent probe to evaluate the biofilm physiological state of Staphylococcus epidermidis, using flow cytometry. Can. J. Microbiol. 2011, 57, 850-856. [CrossRef] [PubMed]

14. Melo, L.D.R.; França, A.; Brandão, A.; Sillankorva, S.; Cerca, N.; Azeredo, J. Assessment of Sep1virus interaction with stationary cultures by transcriptional and flow cytometry studies. FEMS Microbiol. Ecol. 2018, 94, fiy143. [CrossRef]

15. Oliveira, A.; Ribeiro, H.G.; Silva, A.C.; Silva, M.D.; Sousa, J.C.; Rodrigues, C.F.; Melo, L.D.R.; Henriques, A.F.; Sillankorva, S Synergistic Antimicrobial Interaction between Honey and Phage against Escherichia coli Biofilms. Front. Microbiol. 2017,8 , 2407. [CrossRef]

16. Brandão, A.; Pires, D.P.; Coppens, L.; Voet, M.; Lavigne, R.; Azeredo, J. Differential transcription profiling of the phage LUZ19 infection process in different growth media. RNA Biol. 2021, 18, 1778-1790. [CrossRef]

17. Brussaard, C.P. Enumeration of Bacteriophages Using Flow Cytometry. Methods Mol. Biol. 2009, 501, 97-111. [CrossRef]

18. Verthé, K.; Verstraete, W. Use of flow cytometry for analysis of phage-mediated killing of Enterobacter aerogenes. Res. Microbiol. 2006, 157, 613-618. [CrossRef]

19. Low, H.Z.; Böhnlein, C.; Sprotte, S.; Wagner, N.; Fiedler, G.; Kabisch, J.; Franz, C. Fast and Easy Phage-Tagging and Live/Dead Analysis for the Rapid Monitoring of Bacteriophage Infection. Front. Microbiol. 2020, 11, 602444. [CrossRef]

20. Parcey, M.; Gayder, S.; Castle, A.J.; Svircev, A.M. Molecular Profile of Phage Infection: A Novel Approach for the Characterization of Erwinia Phages through qPCR. Int. J. Mol. Sci. 2020, 21, 553. [CrossRef]

21. Wicke, L.; Ponath, F.; Coppens, L.; Gerovac, M.; Lavigne, R.; Vogel, J. Introducing differential RNA-seq mapping to track the early infection phase for Pseudomonas phage $\phi \mathrm{KZ}$. RNA Biol. 2021, 18, 1099-1110. [CrossRef]

22. Fernández, L.; Gutiérrez, D.; García, P.; Rodríguez, A. The Perfect Bacteriophage for Therapeutic Applications—A Quick Guide. Antibiotics 2019, 8, 126. [CrossRef]

23. Lood, C.; Danis-Wlodarczyk, K.; Blasdel, B.G.; Jang, H.B.; Vandenheuvel, D.; Briers, Y.; Noben, J.P.; van Noort, V.; Drulis-Kawa, Z.; Lavigne, R. Integrative omics analysis of Pseudomonas aeruginosa virus PA5oct highlights the molecular complexity of jumbo phages. Environ. Microbiol. 2020, 22, 2165-2181. [CrossRef]

24. Cerca, F.; Andrade, F.; França, A.; Andrade, E.B.; Ribeiro, A.; Almeida, A.A.; Cerca, N.; Pier, G.; Azeredo, J.; Vilanova, M. Staphylococcus epidermidis biofilms with higher proportions of dormant bacteria induce a lower activation of murine macrophages. J. Med. Microbiol. 2011, 60, 1717-1724. [CrossRef]

25. Silveira, M.G.; Romão, M.V.S.; Loureiro-Dias, M.C.; Rombouts, F.M.; Abee, T. Flow Cytometric Assessment of Membrane Integrity of Ethanol-Stressed Oenococcus oeni Cells. Appl. Environ. Microbiol. 2002, 68, 6087-6093. [CrossRef]

26. Pavlova, O.; Lavysh, D.; Klimuk, E.; Djordjevic, M.; Ravcheev, D.A.; Gelfand, M.S.; Severinov, K.; Akulenko, N. Temporal Regulation of Gene Expression of the Escherichia coli Bacteriophage phiEco32. J. Mol. Biol. 2012, 416, 389-399. [CrossRef]

27. Duffy, C.; Feiss, M. The large subunit of bacteriophage $\lambda$ 's terminase plays a role in DNA translocation and packaging termination. J. Mol. Biol. 2002, 316, 547-561. [CrossRef]

28. Bull, J.J.; Gill, J.J. The habits of highly effective phages: Population dynamics as a framework for identifying therapeutic phages Front. Microbiol. 2014, 5, 618. [CrossRef]

29. Pires, D.P.; Sillankorva, S.; Kropinski, A.M.; Lu, T.K.; Azeredo, J. Complete Genome Sequence of Pseudomonas aeruginosa Phage vB_PaeM_CEB_DP1. Genome Announc. 2015, 3, e00918-15. [CrossRef]

30. Pires, D.P.; Monteiro, R.; Mil-Homens, D.; Fialho, A.; Lu, T.K.; Azeredo, J. Designing P. aeruginosa synthetic phages with reduced genomes. Sci. Rep. 2021, 11, 2164. [CrossRef] 
31. Pires, D.P.; Dötsch, A.; Anderson, E.M.; Hao, Y.; Khursigara, C.M.; Lam, J.S.; Sillankorva, S.; Azeredo, J. A Genotypic Analysis of Five, P. aeruginosa Strains after Biofilm Infection by Phages Targeting Different Cell Surface Receptors. Front. Microbiol. 2017, 8 , 1229. [CrossRef]

32. Kropinski, A.M.; Mazzocco, A.; Waddell, T.E.; Lingohr, E.; Johnson, R.P. Enumeration of bacteriophages by double agar overlay plaque assay. Methods Mol. Biol. 2009, 501, 69-76. [CrossRef] [PubMed]

33. Pires, D.P.; Melo, L.D.R. In Vitro Activity of Bacteriophages against Planktonic and Biofilm Populations Assessed by Flow Cytometry. Methods Mol. Biol. 2018, 1693, 33-41. [CrossRef] [PubMed]

34. Pfaffl, M.W. A new mathematical model for relative quantification in real-time RT-PCR. Nucleic Acids Res. 2001, 29, e45. [CrossRef] [PubMed] 